\title{
Stakeholders' Expectations on Human Capital Disclosure vs. Corporate Reporting Practice in Malaysia
}

\author{
Salawati Sahari ${ }^{1}$, Esmie Obrin Nichol ${ }^{1} \&$ Suzila Mohamed Yusof ${ }^{1}$ \\ ${ }^{1}$ Faculty of Economics \& Business, Universiti Malaysia Sarawak \\ Correspondence: Salawati Sahari, Faculty of Economics \& Business, Universiti Malaysia Sarawak, 94300 \\ Samarahan, Sarawak, Malaysia. E-mail: ssalawati@unimas.my
}

Received: November 28, 2018

Accepted: December 27, 2018 Online Published: December 28, 2018

doi:10.5539/ibr.v12n1p148

URL: https://doi.org/10.5539/ibr.v12n1p148

\begin{abstract}
Corporate disclosure of human capital has received growing research attention in different countries and markets. While past studies have explored the antecedent and implications of reporting human capital, studies on how far those disclosure practices actually meet the stakeholders' expectations are still lacking. Hence, this study attempt to apply the stakeholder theory to frame the human capital reporting practices by the corporations in Malaysia. The methodology of this study is twofold; firstly, to develop human capital reporting measurement items as per the stakeholders' expectation and their perceived importance of those items through a Delphi technique, and secondly, to determine the extent of human capital disclosure practices through a content analysis of the annual reports. The findings indicate that despite stakeholders' high perceived importance on human capital disclosures, the corporate reporting practices are still at an inferior stage. This study contributes in such a way to fill the gap in the literature by exploring the current extent of human capital reporting by the listed corporations in Malaysia and how far such disclosure met the stakeholders' expectations. This study also highlights the significance of the stakeholders' voice and participation as one of the main driver towards sustainability reporting.
\end{abstract}

Keywords: human capital reporting, global reporting initiative, stakeholder theory, Delphi techniques, content analysis

\section{Introduction}

Human and intellectual capital is one of, if not, the most prized asset of an organization. As the global economy becomes increasingly knowledge-intensive, so does the value of this intangible asset. This warrants for greater scrutiny of the people-related data, and its contribution on corporate value creation has become an important research issue in recent years. A variety of studies have tested the impact of human capital disclosures in annual reports of companies on corporate value creations (Abeysekera, 2008; Beattie and Smith, 2010), where such value creations were measured differently using both financial and non-financial performance information. Other studies (Lin et al., 2012; Dominguez, 2011; Abeysekara, 2008) tested the impact of human capital disclosures by companies on the market and stakeholders' value.

Most prior studies attempt to measure the human capital reporting by applying the Global Reporting Initiative (GRI) index (Khan et. al., 2011; Cahaya et. al., 2012; Khan et. al., 2011). However, the GRI index may lack certain issues that are deemed significant from the perception of the stakeholders in developing countries. This is because the construction of the GRI index was based on the economies and perceptions of stakeholders of developed countries. Thus, several issues unique to developing countries, such as Malaysia, may not be highlighted in the GRI index.

Existing human capital indicators, as suggested by both the regulations and prior literature may not confirm to the expectations of stakeholders. Moreover, stakeholders may see the need to suggest additional indicators, based on their knowledge and experience. Hence, the motivation of this study is driven by the desire to observe the human capital disclosure items from the personal perspective of key stakeholders, through the collection of primary data from the stakeholders. The contribution of this study to the existing literature could be view by addressing the following research questions:

Research question 1: What type of disclosed information on human capital is considered important from the stakeholders' perception? 
Research question 2: What is the extent of human capital disclosures in the annual reports of listed companies in Malaysia?

Research question 3: Does the information being disclosed by the listed companies meet the expectations of the stakeholders?

Through the Delphi technique, this study among the earliest paper to develop such method to obtain the stakeholders' expectations on human capital disclosure. Furthermore, this study applies the stakeholder theory to model the responsiveness of corporations to disclose human capital activities based on the interests of the various stakeholders. This study aims to examine the extent of the human capital disclosure practices meeting the expectations of the stakeholders. Human capital measurement indicators, perceived to be important by stakeholders, could be used by management of companies to measure the extent of disclosures and serve as a guideline towards sustainable reporting.

\section{Literature Review}

Khan et. al. (2011) highlight several motives behind the use of the GRI guidelines. Firstly, GRI intend to develop a voluntary reporting framework that attempt to stimulate sustainability reporting practices to a level comparable to that of financial reporting in terms of rigour, equivalent, and beyond all, the universal recognition. Secondly, GRI guidelines encompass inclusive measures for both qualitative and quantitative information, and thirdly, GRI provide an organized structure for sustainability reporting. Therefore, this study aims to extend human capital indicators unique to the reporting environment of a developing country, based on the GRI framework and prior studies.

\subsection{Human Capital Indicators}

Human capital indicators cover areas relating to workforce's different level of composition namely different belonging of countries, educational levels, and the type of contracts offered, as well as the sharing of workers with other organisations (Pedrini, 2007).

Abeysekera and Guthrie (2004) introduce the 'headcount of firms' or the total workforce as one of the attributes in the coding framework for their study, which was found to be outside the list of the five most important human capital items. According to them, this probably reflects the fact that firms in Sri Lanka (the sample in that study) are continually restructuring to adopt new technology in order to replace low value-adding activities. They also opine that it could also be one of the reasons why details on the 'vocational qualifications of employees' were least mentioned.

The employment of total number of employees as one of the human capital disclosure index items by Jindal and Kumar (2012) reinforce its relevance for voluntary reporting of human capital. In their study, Jindal and Kumar (2012) breakdown the total number of employees into separate categories according to qualification, gender, caste and experience. Moreover, they employed (1) attrition or turnover rate of the workforce and (2) employee benefits, as other human capital disclosure items.

On the other hand, Abeysekera (2008) found that provision of employee welfare or benefits is effective in curbing absenteeism from work. For instance, respondents for his study (Engineering Ltd. and Toba Ltd.), testified that their firms offer subsidized meals during working hours through their in-house catering facilities in order to increase employee attendance and motivation that will further lead to an increase of capital accumulation.

Similarly, a study by Khan et. al. (2011) also employed 'employment and benefits' as one indicator to measure the extent of disclosure. Their study of banks in Bangladesh found that all the sample banks voluntarily disclosed items on employment and benefits, even though those disclosures are not mandatory. This suggests that the banks in Bangladesh consider provision of employee benefits as an important item for reporting to their stakeholders.

The study by Beattie and Smith (2010) highlights the importance of employee turnover, as an indicator in an employment disclosure. Their respondents recognised that a certain level of turnover was healthy and a valuable contribution in terms of new skills and ideas entering the company. It, therefore, appears that an optimal level of turnover exists, which balances reappointment costs and the benefits of fresh insight. Their respondents revealed that while they want to retain their employees and not have too much turnover, they also acknowledge that zero employee turnover is not necessarily healthy for the company's well-being.

Hence, based on prior literatures and the GRI guidelines, this study selects the following related measurement of human capital reporting. The human capital indicators in Table 1, sourced from the literature, are not the final list 
of indicators. By using them as inputs in the questionnaire to stakeholders, this study aims to discover other pertinent indicator(s).

Table I. Selected human capital disclosure measurement and source of literature

\begin{tabular}{ll}
\hline Human capital disclosure measurement & Sources of standard/ literature/ regulations \\
\hline $\begin{array}{l}\text { Total workforce by employment type, employment contract, and } \\
\text { region. }\end{array}$ & $\begin{array}{l}\text { GRI LA1; Pedrini (2007); Abeysekera and Guthrie } \\
\text { (2004); Jindal and Kumar (2012) }\end{array}$ \\
\hline $\begin{array}{l}\text { Total number and rate of employee turnover by age group, gender, and } \\
\text { region. }\end{array}$ & $\begin{array}{l}\text { GRI LA2; Pedrini (2007); Jindal and Kumar } \\
\text { (2012) }\end{array}$ \\
\hline $\begin{array}{l}\text { Benefits provided to full-time employees that are not provided to } \\
\text { temporary or part-time employees, by major operations. }\end{array}$ & $\begin{array}{l}\text { GRI LA3; Pedrini (2007); Jindal and Kumar } \\
\text { (2012); Khan et. al. (2011), Beattie and Smith } \\
\text { (2010) }\end{array}$ \\
\hline $\begin{array}{l}\text { Composition of governance bodies and breakdown of employees per } \\
\text { category according to gender, age group, minority group membership, } \\
\text { and other indicators of diversity. }\end{array}$ & GRI LA13; Cahaya et. al. (2012); Pedrini (2007) \\
\hline Ratio of basic salary of men to women by employee category. & $\begin{array}{l}\text { GRI LA14; Cahaya et. al. (2012); Khan et. al. } \\
\text { (2011); }\end{array}$ \\
\hline 3. Methodology &
\end{tabular}

\section{Methodology}

\subsection{Delphi Technique}

The Delphi technique is define as a systematic procedure to evoke expert opinion where the intended outcome is to achieve a reliable consensus of opinion among a selected panel of experts (Sourani and Sohail, 2014). The procedure of the Delphi technique could go from one to number of rounds necessary to yield a consensus (Nworie, 2011). The instruments used in such technique are interviews and questionnaires which require feedback from the participants in a predetermined number of rounds.

According to Landeta and Barrutia (2011), the Delphi method allows the most relevant people and collective to take part and contribute their best, within a methodology that channels, encourages and refines their contributions. Moreover, Delphi panel allowed the panels to reduce any negative personal influence or noise that stand in between the communication that is desired and driven the process from the objective of the analysis proposed. Hence, for this study, the panel members are those with numerous understanding and profeciency on human capital in corporations, employee relations and rights, and other related issue being researched. Based on their current and prior positions, they are considered 'experts' who hold a high degree of objectivity and rationality, and are able to apply their knowledge in a professional manner.

The Delphi exercise required that the panel should stay anonymously among each other and willing to participate to the exercise for the three rounds with approximately 6-months period. Therefore, the invitation to the panel were made to ensure the willingness of the panel to fully committed in this study. In order to fulfil the stakeholders' populations, the invitation was made to the stakeholders that represents panel experts in this study which includes shareholders, human resource managers, employee representatives of listed company, internal and external labor union representative, related ministry of human capital, officer related to corporate reporting and payroll, non-governmental agency related to labor protection activity and other educational experts of human capital.

The Delphi technique in this study aims to obtain the stakeholders' perception on the human capital indicators initially constructed from the GRI and prior literature (as shown in Table 1). The final list of indicators, to be applied in the content analysis of the annual reports of listed Malaysian companies, will be drawn from the perceptions and opinions of stakeholders or the panel.

\subsection{The Delphi Panel}

According to Weidman, et. al. (2011), the literature has not specified the number of experts needed for a Delphi technique. Members of the panel are selected because they have vast knowledge and experience in dealing with human capital of corporations, employee relations and rights, and the issue being researched. As for this study, a total of twelve experts have accepted the formal invitation to be in the panel, representing a wide spectrum of human capital professionals in Malaysia with two from the public sector, one from a non-governmental organization (NGO), and nine from the private sector.

\subsection{Secondary Data Collection: Content Analysis}

Content analysis for this study examines the human capital disclosures in the annual reports of listed companies in Malaysia (for the year 2014), based on the indicators previously obtained from the Delphi technique. The extent of human capital disclosure is measured on a dichotomous basis $(0,1)$. This approach is consistent with 
prior studies (Cahaya, 2012; Jindal and Kumar, 2012).

The reason to choose a dichotomous approach in this study was because it is more objective as it avoids scaling errors (Abeysekera, 2010). Furthermore, Cahaya (2012) stated that this method as a more relevant technique to be applied to all different type of companies since it is considered as a far less subjective approach than the weighted approach. As for Leventis and Weetman (2004), they stated that using both weighted and unweighted approach resulted the same conclusions and hence, suggested the application of unweighted disclosure index since it is the most commonly used method from prior literature. Elsayed (2010) argues that the unweighted disclosure index is more preferable since the weighted disclosure index depends on the respondent such as users, whose opinions are used in deciding the weights of some items of information, in general, lack self-insight regarding their own use of information. Further, Elsayed (2010) stated that, assigning scores for disclosed items of information depending on eliciting subjective opinions from a user group that may be misleading, because the level of usefulness which is assigned to each disclosure item is not absolute, rather it varies depending on the country, the user, the industry and the time of the study. Mangena and Pike (2005) employ the unweighted disclosure index because they argue that weighting of disclosure items does not alter the results significantly as companies disclose important items as much as they disclose unimportant items.

The dichotomous approach used in scoring the extent of human capital disclosure assigns a 0 if an item in the index does not appear in the annual report and a value of 1 if an item is disclosed. A scoring sheet that consisted of all the human capital disclosure items as obtained from the Table 1 was used to facilitate the scoring process and to ensure the consistency of scoring process. The scoring procedure by using the human coding method whereby each annual report will be read thoroughly. Since the human rights disclosure in the annual report is a voluntary disclosure and descriptive in nature, the following sections were selected in the annual report for thorough reading, selection and evaluation for the scoring procedure:

1. Corporate social responsibility statement

2. Sustainability report

3. Statement on corporate governance

4. Chairman's (or managing director's) statement

5. Statistic highlights

6. Additional compliance information

7. Code of conduct and business ethics

8. Statement on risk management and internal control

9. Administration report

The researcher than highlights all the available measurement items (key words as such in Table 1) in the annual report and remarks the code for the measurement item in the printed annual report sections. After all the annual reports are remarks with the relevant code, the score than, were keyed-in in the master worksheet with the column pre-set for each human capital disclosure and the number and the name for each corporation for each row. The scoring process was based on the dichotomous basis where the human capital disclosure assigns " 0 " if an item in the index does not appear in the annual report and value of "1" if an item is disclosed. When the scoring of the companies was completed, each company ended up with a composite score reflecting the number of disclosure items against which it was found to have made disclosures in its annual report. This process of coding procedure is the coding for unweighted index.

\section{Findings}

\subsection{Results from the Delphi Technique}

The initial round of the Delphi technique presented the panel members with a questionnaire featuring the items in Table II, which may be perceived by the respondents as important (yes) and not important (no). Chan, et. al. (2001) stated that items having a score in excess of 50\% are deemed important and will be selected for further consideration in the next round of the Delphi method. Hence, it could be seen from Table II, that all items were considered important. At the initial round, some panel members suggested a new item 'Compliance with minimum wage policy'. This new item was included in the second round of the Delphi technique, and was given a coding B1. 
Table II. Percentage of responses from round one

\begin{tabular}{llll}
\hline & & \multicolumn{2}{c}{ Q1 (in percentage) } \\
& & No & Yes \\
\hline A1 & Total workforce & 0 & 100 \\
A2 & Employee turnover & 8 & 92 \\
A3 & Benefits for full time employees & 16 & 84 \\
A4 & Breakdown of employees per category & 16 & 84 \\
A5 & Salary by employee category & 42 & 58 \\
\hline
\end{tabular}

In the second round, one of the panel have withdrawn to proceeds with this study, which therefore, only eleven panel experts proceed with the second and third round of Delphi exercise. each panel member was invited to reconsider his/her initial responses given in round one. Questionnaire for Round 2 was constructed using a five-point Likert scale. The panel had to reconsider the importance of each item of human capital disclosure by selecting a degree of importance $(0=$ very unimportant, $1=$ unimportance, $2=$ quite important, $3=$ very important, 4 = extremely important). Table III shows Round 2 results in percentage.

Table III. Percentage of responses from round two

\begin{tabular}{|c|c|c|c|c|c|c|}
\hline & & $\mathbf{0}$ & 1 & 2 & 3 & 4 \\
\hline A1 & Total workforce & 0 & 9 & 18 & 18 & 55 \\
\hline $\mathrm{A} 2$ & Employee turnover & 0 & 18 & 9 & 36 & 36 \\
\hline A3 & Benefits for full time employees & 0 & 9 & 9 & 45 & 36 \\
\hline B1 & Compliance with minimum wage policy & 0 & 0 & 18 & 18 & 64 \\
\hline A4 & Breakdown of employees per category & 0 & 0 & 45 & 45 & 9 \\
\hline A5 & Salary by employee category & 9 & 18 & 27 & 36 & 9 \\
\hline
\end{tabular}

Table IV shows the percentage response for each degree of importance from the Delphi Round 3. Despite the same panel and similar questionnaire, the findings from Round 2 and 3 are different. However, it should be highlighted that the panel had to review the findings from Delphi Round 2 before they could give their input in the Delphi Round 3.

Table IV. Percentage of responses from round three

\begin{tabular}{|c|c|c|c|c|c|c|}
\hline & & $\mathbf{0}$ & 1 & 2 & 3 & 4 \\
\hline A1 & Total workforce & 0 & 9 & 36 & 27 & 27 \\
\hline $\mathrm{A} 2$ & Employee turnover & 0 & 9 & 36 & 46 & 9 \\
\hline A3 & Benefits for full time employees & 0 & 0 & 46 & 18 & 36 \\
\hline B1 & Compliance with minimum wage policy & 0 & 9 & 18 & 18 & 55 \\
\hline A4 & Breakdown of employees per category & 0 & 0 & 18 & 36 & 46 \\
\hline A5 & Salary by employee category & 9 & 0 & 18 & 27 & 46 \\
\hline
\end{tabular}

\subsection{Level of Consensus of the Responses}

The major objective for conducting Delphi is to obtain a reliable consensus among participating experts. The aim of the consensus is to determine the extent to which experts or lay people agree about a given issue. The level of consensus in this study is measured by the percentage of respondents agreeing. Huges (2003) defined consensus descriptors as those descriptors that were regarded as "important" or "very important" by more than $83 \%$ of the responses. As for Kilner (2004), the terms agreement being implied by the results, or more specifically in numerical terms such as 55\% or $100 \%$. Sourani and Sohail (2014) observed agreement among respondents that a certain criterion is important based on having $75 \%$ or more of the respondents agreeing on giving a ranking.

In order to observe stability among respondents, the percentage respondents agreeing on giving a ranking that is equal to or more than 2 (quiet important) are calculated. Similar method was done in a study by Sourani and Sohail (2014). For instance, under the category of A1 Total Workforce (refer to Table IV), percentage of responses agreeing from column 2, 3 and 4 are 36\%, 27\% and 27\% respectively, which indicate a total of 90\%. Since these total are more than $75 \%$, this indicates the panel's agreement. As what can be seen from the Table IV (total percentage for column 2,3 and 4), almost all the item in the questionnaire have reach a total percentage of more than $75 \%$, indicating the panel's agreement. This indicates the consensus have been met in the round 3 .

\subsection{Finalization of the Human Capital Disclosure Index}

The expert panel's agreement on the human capital disclosure information and the importance of each item was developed into an index. Table V shows the human capital disclosure items established from the Delphi exercise and their level of importance. It can be seen that the panel viewed all items as important, with a weighting of 2.5 and above, given that the scale of 2 denotes 'quiet important' in the questionnaire. 
Table V. List of human capital disclosure items and their importance weightings

\begin{tabular}{lll}
\hline & & $\begin{array}{l}\text { Importance } \\
\text { weightings }(0-4)\end{array}$ \\
\hline A1 & Total workforce & 2.7273 \\
A2 & Employee turnover & 2.5455 \\
A3 & Benefits for full time employees & 2.9091 \\
B1 & Compliance with minimum wage policy & 3.1818 \\
A4 & Breakdown of employees per category & 3.2727 \\
A5 & Salary by employee category & 3.0000 \\
\hline
\end{tabular}

4.4 The Extent of Human Capital Disclosure

Table VI summarizes the human capital disclosure frequency and the percentage of disclosure in the annual reports of 792 listed companies for the year 2014, which was obtained from the content analysis technique. In general, the percentage of disclosure is seen to be very low, with the highest being a mere $11.2 \%$ of the 792 companies disclosing the item 'breakdown of employees per category'.

Table VI. Human capital disclosure frequency and percentage of disclosure

\begin{tabular}{llccc}
\hline & & Non-Disclosure & Disclosure & Percentage of disclosure \\
\hline A1 & Total workforce & 704 & 88 & $11.1 \%$ \\
A2 & Employee turnover & 769 & 23 & $2.9 \%$ \\
A3 & Benefits for full time employees & 749 & 43 & $5.4 \%$ \\
A4 & Compliance with minimum wage policy & 780 & 12 & $1.5 \%$ \\
E2 & Breakdown of employees per category & 703 & 89 & $11.2 \%$ \\
E3 & Salary by employee category & 788 & 4 & $0.5 \%$ \\
\hline
\end{tabular}

\section{Discussions}

\subsection{The Human Capital Disclosure vs. the Stakeholders' Expectations}

Table VII indicates descriptive statistics for the percentage of human capital disclosure as compared to the experts' (or stakeholders') weighting for importance. The percentage of disclosure for all items is seen to be very low, with the highest disclosure rate of only $11.2 \%$. In comparison, the experts' weighting for importance indicates the stakeholders perceived most of the item as more than just 'quite important', with a score of above 2.55 (Likert-scale of 0 - 4).

Table VII. Human capital disclosure and stakeholders' weighting of importance

\begin{tabular}{lcc}
\hline & $\begin{array}{c}\text { Experts' weighting for } \\
\text { importance }\end{array}$ & Percentage of disclosure \\
\hline Total workforce & 2.73 & $11.1 \%$ \\
Employee turnover & 2.55 & $2.9 \%$ \\
Benefits for full time employees & 2.91 & $5.4 \%$ \\
Compliance with minimum wages policy & 3.18 & $1.5 \%$ \\
Breakdown of employees per category & 3.27 & $11.2 \%$ \\
Salary by employee category & 3.00 & $0.5 \%$ \\
\hline
\end{tabular}

The 'compliance with minimum wage policy', an additional item suggested by the expert panel, is considered highly important by the experts, whereas the extent of disclosure among listed companies is the lowest. This is because compliance with minimum wage policy took effect only recently in 2012, and the annual reports content analysed were for the year 2014.

On a similar note, the companies' disclosure for the item 'employee turnover', that is perceived by the experts to be important (weighting of 2.55), is also found to be poor, as indicated by the low level of importance at $2.9 \%$. This is consistent with Cahaya et. al (2012) finding of a low percentage of disclosure for the item 'total number and rate of employee turnover by age group, gender, and region' at only $5.83 \%$ of listed companies in Indonesia during the year 2007.

\subsection{Reasoning Through Stakeholder Theory}

The Delphi technique was performed towards the panel which was mostly come from the stakeholders which was define as someone who have a stake or a reasonable demand in the company (Tullberg, 2013). Hence, in the Delphi technique, the key stakeholders are identified with the best interest with the research area of this study.

Stakeholders may be "mistaken" in their value judgments whereby, they may not be neutral in judging what is best for them or for related matters such as human resource, labour rights, and policy. This raises an important issue. Even though it might be adequate from stakeholder theory perspective to argue that what really matters are stakeholders' subjective judgments, this is unlikely to avail from a normative perspective. Therefore, the subjective and judgemental value of stakeholders towards the human capital might have led to their high interest 
and placing of human capital items at a high level of importance regardless of low level of disclosure practice by the management.

Furthermore, the contradictions between the stakeholders' high expectations and low level of human capital disclosures could be related to the "power" point of view. According to Buren and Greenwood (2011), stakeholders are dependent upon the business entity by virtue of their stake; however, the degree to which the firm is dependent on the stakeholder varies. Even withholding their labour from the organization provides little power (especially in environments in which trade unions do not exist or are suppressed) because these employees are more dependent on their employers for their remuneration than their employers are on them for their labour. Furthermore, employers may perceive (with some justification) any particular group of workers as easy to replace.

Stakeholder theory could focus on a libertarian argument, positing that when corporations engage in voluntary corporate social reporting, then the hand of the state is less likely to restrict business decision making. It is helpful to consider how stakeholders can serve as constraints on the power of managers (Fox, 1971), or in the case employees with unfair treatment, do not have much ability to serve as such. Analyses of power suggest that holding it allows a stakeholder group to constrain the behaviour of managers and to seek terms of exchange that are more favourable to the stakeholder. However, some employees do not possess power, and in the absence of a coalition with a powerful stakeholder group are likely not to have their claims heard or to be able to affect the terms of exchange with their employers in ways that are salutary to employees' interests.

\section{Conclusions}

The main objective of this study is to ascertain whether the information on human capital disclosure in the annual reports meets the stakeholders' expectations. The low percentage of disclosures by the listed companies suggests low level of importance placed on reporting of human capital items. This contradicts the high expectations of the panel of experts on the importance of disclosing such items. This stipulates that despite the high expectations of the panel experts on the importance to disclose the human capital items, the disclosure is still at a poorer stage.

The stakeholder theory attempts to explain this finding: (1) The judgmental value of the stakeholders could drive the stakeholders to perceive the human capital issues as important due to their high interest on the subject matter, (2) Stakeholders with lower level of power cannot control the management's decision, and (3) Stakeholder-management relationship is such that the stakeholders are dependent on the management and, therefore, cannot challenge the management's decision.

The low levels of disclosure practice by the listed companies are open to debate. As for the case of employees' rights, several important issues are obviously unfair treatment. However, the demand to disclosure such issue on employees' rights maybe known by the companies, though the question was that how far the stakeholders' voice has reach the company?

It has been argued that stakeholder contribution to value creation implies a right to some sort of voice in its relations with a corporation or other organization. A decline in employee voice, both for individual employees and employees as a group, is well documented (Freeman et al., 2007). The loss of voice is particularly acute for low-wage employees. But there are other powerless stakeholders that lack voice as well, such as communities in poor countries. Many would argue that even shareholders lack voice. Hence, this study concludes that stakeholder voice and participation in organizational decision making is addressed may needs further development. Further study could being develop by focusing on employees' rights disclosure practice and the stakeholders' voice on such issue of employees' rights.

\section{Acknowledgements}

The authors wish to thank Ministry of Higher Education for funding this research through the Fundamental Research Grant Scheme (F01/FRGS/1605/2017).

\section{References}

Abeysekera, I. (2008). Motivations behind human capital disclosure in annual reports. Accounting Forum, 32, 16-29. https://doi.org/10.1016/j.accfor.2006.11.006

Abeysekera, I., \& Guthrie, J. (2004). An empirical investigation of annual reporting trends of intellectual capital in Sri Lanka. Critical Perspectives on Accounting, 16, 151-163.

https://doi.org/10.1016/S1045-2354(03)00059-5

Beattie V., \& Smith, S. J. (2010). Human capital, value creation and disclosure. Journal of Human Resource 
Costing \& Accounting, 14(4), 262-285. https://doi.org/10.1108/14013381011105957

Buren, H. J. V., \& Greenwood, M. (2011). Bringing stakeholder theory to industrial relations. Employee Relations, 33(1), 5-21. https://doi.org/10.1108/01425451111091627

Cahaya, F. R., Porter, S. A., Tower, G., \& Brown, A. (2012). Indonesia's low concern for labor issues. Social Responsibility Journal, 8(1), 114-132. https://doi.org/10.1108/17471111211196610

Chan, A. P. C., Yung, E. H. K., Lam, P. T. I., Tam, C. M., \& Cheung, S. O. (2001). Application of Delphi method in selection of procurement systems for construction projects. Construction Management and Economics, 19(7), 699-718. https://doi.org/10.1080/01446190110066128

Dominguez, A. A. (2011). The impact of human resource disclosure on corporate image. Journal of Human Resource Costing \& Accounting, 15(4), 279-298. https://doi.org/10.1108/14013381111197225

Elsayed, M. O., \& Hoque, Z. (2010). Perceived international environmental factors and corporate voluntary disclosure practices: an empirical study. The British Accounting Review, 42, 17-35. https://doi.org/10.1016/j.bar.2010.01.001

Fox, A. (1971). A Sociology of Work in Industry. London: Collier-Macmillan Limited.

Freeman, R. B., Boxall, P., \& Haynes, P. (2007). What Workers Say: Employee Voice in the Anglo-American Workplace. NY: ILR Press, Ithaca.

Hughes, R. (2003). Definitions for public health nutrition: a developing consensus. Public Health Nutrition, 6(6), 615-620. https://doi.org/10.1079/PHN2003487

Jindal, S., \& Kumar, M. (2012). The determinants of HC disclosures of Indian firms. Journal of Intellectual Capital, 13(2), 221-247. https://doi.org/10.1108/14691931211225049

Khan, M. H., Islam, M. A., Fatima, J. K., \& Ahmed, K. (2011). Corporate sustainability reporting of major commercial banks in line with GRI: Bangladesh evidence. Social Responsibility Journal, 7(3), 347-362. https://doi.org/10.1108/17471111111154509

Kilner, T. (2004). Desirable attributes of the ambulance technician, paramedic, and clinical supervisor: findings from a Delphi study. Emergency Medicine Journal, 21, 374-378. https://doi.org/10.1136/emj.2003.008243

Leventis, S., \& Weetman, P. (2004). Voluntary disclosures in an emerging capital market: some evidence from the Athens Stock Exchange. Advances in International Accounting, 17, 227-250. https://doi.org/10.1016/S0897-3660(04)17011-6

Lin, L. S., Huang, I. C., Du, P. L., \& Lin, T. F. (2012). Human capital disclosure and organizational performance: The moderating effects of knowledge intensity and organizational size. Management Decision, 50(10), 1790-1799. https://doi.org/10.1108/00251741211279602

Mangena, M., \& Pike, R. (2005). The effect of audit committee shareholding, financial expertise and size on interim financial disclosures. Accounting and Business Research, 35(4), 327-349. https://doi.org/10.1080/00014788.2005.9729998

Nworie, J. (2011). Using the Delphi technique in educational technique in educational technology research. TechTrends, 55(5), 24-30. https://doi.org/10.1007/s11528-011-0524-6

Pedrini, M. (2007). Human capital convergences in intellectual capital and sustainability reports. Journal of Intellectual Capital, 8(2), 346-366. https://doi.org/10.1108/14691930710742880

Sourani, A., \& Sohail, M. (2014). The Delphi method: Review and use in construction management research. International Journal of Construction Education and Research, 00, 1-23.

Weidman, J. E., Miller, K. R., Christofferson, J. P., \& Newitt, J. S. (2011). Best practices for dealing with price volatility in commercial construction. International Journal of Construction Education and Research, 7(4), 276-293. https://doi.org/10.1080/15578771.2011.552936

\section{Copyrights}

Copyright for this article is retained by the author(s), with first publication rights granted to the journal.

This is an open-access article distributed under the terms and conditions of the Creative Commons Attribution license (http://creativecommons.org/licenses/by/4.0/). 